\title{
Functional rare variant in a C/EBP beta binding site in NINJ2 gene increases the risk of coronary artery disease
}

\author{
Pengyun Wang ${ }^{1, *}$, Yifan Wang ${ }^{2,}{ }^{,}$, Huixin Peng ${ }^{2,}$, Jingjing Wang ${ }^{3}$, Qian Zheng ${ }^{2}$, Pengxia Wang ${ }^{2}$, \\ Jing Wang ${ }^{2}$, Hongfu Zhang ${ }^{2}$, Yufeng Huang ${ }^{4}$, Liang Xiong ${ }^{1}$, Rongfeng Zhang ${ }^{5}$, Yunlong Xia ${ }^{5}$, Qing \\ K. Wang ${ }^{2}$, Chengqi $\mathrm{Xu}^{2}$ \\ ${ }^{1}$ Department of Clinical Laboratory, Liyuan Hospital of Tongji Medical College, Huazhong University of Science and \\ Technology, Wuhan, PR China \\ ${ }^{2}$ Human Genome Research Center, Cardio-X Institute, College of Life Science and Technology of Huazhong \\ University of Science and Technology, Wuhan, PR China \\ ${ }^{3}$ State Key Laboratory for Molecular and Developmental Biology, Institute of Genetics and Developmental Biology, \\ Chinese Academy of Sciences, Beijing, PR China \\ ${ }^{4}$ Precision Medical Laboratory, Tongji Medical College, Wuhan Children's Hospital (Wuhan Maternal and Child \\ Health Care Hospital), Huazhong University of Science and Technology, Wuhan, PR China \\ ${ }^{5}$ Department of Cardiology, First Affiliated Hospital of Dalian Medical University, Dalian, PR China \\ *Equal contribution and share first authorship
}

Correspondence to: Chengqi Xu; email: cqxu@mail.hust.edu.cn

Keywords: coronary artery disease, genetics, SNP, NINJ2, C/EBP beta

Received: October 30, $2020 \quad$ Accepted: November 11, $2021 \quad$ Published: December 12, 2021

Copyright: (C) 2021 Wang et al. This is an open access article distributed under the terms of the Creative Commons Attribution License (CC BY 3.0), which permits unrestricted use, distribution, and reproduction in any medium, provided the original author and source are credited.

\section{ABSTRACT}

Objective: NINJ2 regulates activation of vascular endothelial cells, and genome-wide association studies showed that variants in NINJ2 confer risk to stroke. However, whether variants in NINJ2 are associated with coronary artery disease (CAD) is unknown.

Methods: We genotyped rs34166160 in NINJ2 in two independent Chinese GenelD populations which included 2,794 CAD cases and 4,131 controls, and performed genetics association studies. Functional studies were also performed to reveal the mechanisms.

Results: Allele rs34166160 significantly confers risk to CAD in the GenelD Hubei population which contained 1,440 CAD cases and 2,660 CAD-free controls (observed $P_{\text {-obs }}=6.39 \times 10^{-3}$ with an odds ratio (OR) was 3.39, adjusted $P_{-a d j}=8.12 \times 10^{-3}$ with an OR of 3.10). The association was replicated in another population, GeneID Shandong population contained 1,354 CAD cases and 1,471 controls $\left(P_{-o b s}=3.33 \times 10^{-3}\right.$ with an OR of 3.14, $P_{-a d j}=0.01$ with an OR of 2.74). After combining the two populations, the association was more significant $\left(P_{-o b s}=1.57 \times 10^{-5}\right.$ with an OR of $3.58, P_{-a d j}=3.41 \times 10^{-4}$ with an OR of 2.80). In addition, we found that rs34166160 was associated with the mRNA expression level of NINJ2 and the flanking region of rs34166160 can directly bind with transcriptional factor CCAAT-box/enhancer-binding protein beta, and the risk A allele has more transcription activity than non-risk $C$ allele with or without LPS in HUVEC cells.

Conclusions: Our study demonstrates that the functional rare variant rs34166160 in NINJ2 confers risk to CAD for the first time, and these findings further expand the range of the pathology of CAD and atherosclerosis. 


\section{INTRODUCTION}

Atherosclerosis is the leading pathological cause of coronary heart disease (CAD) and ischemic stroke, which claims about 14 million of lives every year and is the main cause of mortality and morbidity worldwide $[1,2]$. In China, CAD and stroke are also one of the most common public health problems, and account for $40 \%$ of all deaths every year.

Atherosclerosis is a complex trait caused by environmental factors, genetic factors, and their interactions [3]. Risk factors such as abnormal lipid concentrations, obesity, diabetes, smoking, hypertension, physical inactivity, psychosocial situations, and alcohol intake are shared among CAD and ischemic stroke $[4,5]$. In addition, epidemiological data shows that genetic background plays a critical role in both CAD and ischemic stroke [6]. Genetic analysis in families or population, such as genome-wide association studies (GWAS) revealed a lot of susceptibility genes/loci confer risk to the incidence of CAD or ischemic stroke, and some of them, including ANRIL in 9p21, PCSK9 in 1p32 and BRG1 in 19p13 were found to confer risk for both CAD and ischemic stroke [7]. Identification of novel genetic risk variants that are shared by both ischemic stroke and CAD may identify the underlying pathophysiology of atherosclerosis, and facilitate diagnosis, which may ultimately lead to prevention and treatment of ischemic stroke and CAD.

In a previous study, we found that ninjurin2 (encode by NINJ2) is expressed in human vascular endothelial cells, and can regulate the expression of genes associated with inflammation and atherosclerosis (IL$1 \beta$, TNF- $\alpha$, IL-8, IL-6, ICAM- 1 and E-selectin) in HUVECs. Moreover, we found ninjurin 2 can regulate LPS-induced endothelial activation, and the adhesion of monocytes to endothelial cells through the TLR4/ $\mathrm{NF}-\kappa \mathrm{B} / \mathrm{c}-\mathrm{jun}$ pathway [8], which proposed that ninjurin2 is a novel regulator of endothelial activation, and may play important roles in the initiation or development of atherosclerosis. Endothelial activation is a crucial step in the initiation and development of the atherosclerosis process. Under irritant stimuli, including dyslipidemia, hypertension, and pro-inflammatory agents, vascular endothelial cells were activated and support monocyte migration into the sub-endothelial space, and then differentiate into macrophages and take up modified lipoproteins to become lipid-laden foam cells. After activation, the normal functions of the arterial endothelium are adversely affected, and this leads to atherosclerosis and cardiovascular diseases, such as CAD and ischemic stroke.
Previously, GWAS and candidate gene based association studies have shown that variants in the NINJ2 gene confer risk to the incidence of ischemic stroke in several independent populations, including Chinese, Korean, Iranian and Caucasian ancestry [9-14], however, the detailed mechanisms of how NINJ2 regulates endothelial activation are not very clear, and the relationship between NINJ2 and endothelial activation also need to be confirmed in other type of atherosclerosis related disease including CAD.

Here, we tested the hypothesis that the association between rs34166160 in NINJ2 and CAD, which is a low-frequency variant associated with ischemic stroke in Caucasians [15]. We identified rs34166160 in NINJ2 as a novel genetic risk factor of CAD in the Chinese Han population. Expression quantitative trait loci (eQTLs) were identified between rs34166160 and NINJ2 mRNA expression in Blood cells. Our further functional studies also demonstrated that the risk A allele of rs34166160 has more transcription activity than the non-risk $\mathrm{C}$ allele using the Electrophoretic Mobility Shift Assay (EMSA) and Luciferase Reporter Assay, and may cooperate with transcriptional factor C/EBP beta under the LPS induced endothelial activation. Our data identified rs34166160 in NINJ2 as a susceptibility locus for CAD, and uncovered a potential mechanism of rs34166160 conferring risk to $\mathrm{CAD}$ via regulating the expression of NINJ2 by binding with C/EBP beta.

\section{RESULTS}

\section{Characteristics of study subjects}

The samples involved in the current research were selected from the GeneID cohort [16-23]. To avoid geographical confounding, our genetic association studies between polymorphisms and disease were carried out in two independent populations. The GeneID-Central population, which contained 1,440 cases with $\mathrm{CAD}$ and 2,660 CAD-free controls, was collected from central China (Hubei province). The GeneID-North population consists of 1, 354 CAD patients and 1,471 CAD-free controls, and are selected from the patients in hospitals in the northern area of China.

Basic clinical and demographic characteristics of the study populations were shown in Table 1. Initially, the association analysis was conducted in the GeneIDCentral population that included 1,440 CAD cases and 2,660 non-CAD controls as a discovery population. The mean ages for cases and controls were $60.42 \pm 12.14$ and $61.25 \pm 9.83$ years, respectively in the GeneIDCentral population. The proportions of females in cases 
Table 1. Basic demographic and clinical characteristics of CAD patients and controls involved in the present study.

\begin{tabular}{|c|c|c|c|c|}
\hline \multirow[b]{2}{*}{ Characteristic } & \multicolumn{2}{|c|}{ GeneID-Central Population } & \multicolumn{2}{|c|}{ GeneID-North Population } \\
\hline & $\begin{array}{c}\text { Cases } \\
(n=\mathbf{1 , 4 4 0})\end{array}$ & $\begin{array}{c}\text { Controls } \\
(n=2,660)\end{array}$ & $\begin{array}{c}\text { Cases } \\
(n=1,354)\end{array}$ & $\begin{array}{c}\text { Controls } \\
(n=1,471)\end{array}$ \\
\hline $\mathrm{Age}^{\mathrm{a}}$, mean $\pm \mathrm{SD}$, years & $60.42 \pm 12.14$ & $61.25 \pm 9.83$ & $63.67 \pm 12.69$ & $62.17 \pm 10.13$ \\
\hline Sex, Female, $n($ No. $\%)$ & $558(38.75 \%)$ & $1,021(38.38 \%)$ & $604(44.60 \%)$ & $678(46.09 \%)$ \\
\hline Hypertension $^{\mathrm{b}}, n$ (No. \%) & $861(59.80 \%)$ & $1,566(58.87 \%)$ & $827(61.08 \%)^{* * *}$ & $765(52.0 \%)$ \\
\hline Diabetes $^{\mathrm{c}}, n($ No. $\%)$ & $211(14.65 \%)^{*}$ & $327(12.30 \%)$ & $225(16.62 \%)^{* *}$ & $191(12.99 \%)$ \\
\hline Total Cholesterol, mean $\pm \mathrm{SD}, \mathrm{mmol} / \mathrm{L}$ & $4.39 \pm 1.07^{*}$ & $4.31 \pm 0.85$ & $4.45 \pm 1.11^{*}$ & $4.37 \pm 1.02$ \\
\hline Triglyceride, mean $\pm \mathrm{SD}, \mathrm{mmol} / \mathrm{L}$ & $1.55 \pm 1.12^{*}$ & $1.44 \pm 1.03$ & $1.48 \pm 1.29^{*}$ & $1.40 \pm 1.33$ \\
\hline $\mathrm{HDL}-\mathrm{C}$, mean $\pm \mathrm{SD}, \mathrm{mmol} / \mathrm{L}$ & $1.18 \pm 0.44$ & $1.22 \pm 0.38$ & $1.10 \pm 0.38$ & $1.17 \pm 0.45$ \\
\hline $\mathrm{LDL}-\mathrm{C}$, mean $\pm \mathrm{SD}, \mathrm{mmol} / \mathrm{L}$ & $2.71 \pm 0.80^{* *}$ & $2.51 \pm 0.83$ & $2.64 \pm 0.85^{*}$ & $2.55 \pm 0.66$ \\
\hline
\end{tabular}

Data are shown as mean $+/-$ standard deviation (SD) for quantitative variables and percent (\%) for qualitative variables. ${ }^{*} P<$ $0.05,{ }^{* *} P<0.01$ and ${ }^{* * *} P<0.001$ between cases and controls for quantitative variables and percent (\%) for qualitative variables. ${ }^{\mathrm{a}} \mathrm{Age}$ at the first diagnosis of the disease in CAD case and at enrollment of CAD controls. ${ }^{\mathrm{b}} \mathrm{Hypertension}$ was defined as a systolic blood pressure of $\geqq 140 \mathrm{mmHg}$ or a diastolic blood pressure of $\geqq 90 \mathrm{mmHg}$. 'Diabetes was defined as ongoing therapy of diabetes or a fasting plasma glucose level of $\geq 7.0 \mathrm{mmol} / \mathrm{L}$.

and controls was $38.75 \%$ and $38.38 \%$, respectively (Table 1). Association from the discovery population was then verified in another independent replication case-control population (GeneID-North population) and included 1,354 cases and 1,471 controls. The GeneIDNorth population included $44.60 \%$ females in cases and $46.20 \%$ in controls. The mean age for the cases was $63.67 \pm 12.69$ years versus $62.17 \pm 10.13$ years for controls (Table 1).

\section{Variant rs34166160 in NINJ2 associates with CAD in two independent populations}

The genotype of rs34166160 did not deviate from the Hardy-Weinberg equilibrium in controls in both the discovery GeneID-Central population $(p=0.99)$ and the replication GeneID-North population $(p=0.99)$. The allelic frequencies of rs34166160 in CAD cases were significantly different from those in controls in the discovery GeneID-Central population (Table 2). The frequency of minor A allele of rs34166160 was $0.44 \%$ in CAD cases and $0.13 \%$ in controls. A significant association was identified with an unadjusted $p$ value $\left(p_{-o b s}\right)$ of $6.39 \times 10^{-3}$ and an OR of 3.39. The association was also significant (an adjusted $p$ or $p_{-a d j}=8.12 \times 10^{-3}$ with and OR of 3.10) after adjusting for covariates (diabetes mellitus, age, hypertension, gender, and plasma lipid concentrations) (Table 2).

To further validate the association between rs34166160 and CAD, we genotype for the rs34166160 variant in the replication GeneID-North population that contained 1,354 CAD cases and 1,471 controls. Interestingly, we also found that the A allele of the rs34166160 variant confers risk to CAD ( $p_{-o b s}=3.33 \times 10^{-3}$ with an OR of $3.14 ; p_{\text {-adj }}=0.01$ with an OR of 2.74) in the replication population (Table 2).

After performing a meta-analysis, two populations were combined to yield one large population that included 2,794 cases and 4,131 controls. In the combined population, SNP rs34166160 was found to confer a highly significant risk to $\mathrm{CAD}\left(p_{\text {-obs }}=1.57 \times 10^{-5}\right.$, $\mathrm{OR}=3.58$ ). Moreover, after adjustment for covariates including sex and age, this association remained significant $\left(p_{\text {-adj }}=3.41 \times 10^{-4}, \mathrm{OR}=2.80\right)$ in the combined population. These results showed that A allele of rs34166160 in the NINJ2 gene was significantly associated with $\mathrm{CAD}$ in the studied Chinese population.

Real-time RT-PCR analysis identified that the A allele of rs34166160 is associated with the increased expression level of $N I N J 2$ mRNA

Rs34166160 (Chr12:623,339, hg38 version of human genome data) is located in the first intron of the NINJ2 gene. Bioinformatical analysis predicts that rs 34166160 is located in an enhancer region according to the Ensembl database (Regulatory Feature: ENSR00000047562, Chr12:621,401-623,800, hg38, http://asia.ensembl.org/), and in a DNase I hypersensitive cluster (chr12:623,241-623,470) in ENCODE data of UCSC genome browser (https://genome.ucsc.edu). ENCODE Candidate CisRegulatory Elements (cCREs) also showed that rs34166160 was predicted to be located in an enhancer of NINJ2 (Chr12:623,197-623,527, ENCODE Accession: EH38E1585530). 
Table 2. Analysis of allelic association of SNP rs34166160 with CAD in the Chinese Han population.

\begin{tabular}{|c|c|c|c|c|c|c|}
\hline \multirow{2}{*}{$\begin{array}{l}\text { Populations } \\
\text { (n, case/control) }\end{array}$} & \multirow{2}{*}{$\begin{array}{l}\text { Risk } \\
\text { Allele }\end{array}$} & \multirow{2}{*}{$\begin{array}{l}\text { Frequency } \\
\text { (case/control) }\end{array}$} & \multicolumn{2}{|c|}{ Without Adjustment $^{\mathbf{a}}$} & \multicolumn{2}{|c|}{ With Adjustment $^{\mathrm{b}}$} \\
\hline & & & $P$-obs & OR $(95 \%$ CI $)$ & $P$-adj & OR $(95 \%$ CI $)$ \\
\hline $\begin{array}{l}\text { GeneID-Central } \\
\text { Population }(1,440 / 2,660)\end{array}$ & A & 0.0045 vs. 0.0013 & $6.39 \times 10^{-3}$ & $3.39(1.33-8.63)$ & $8.12 \times 10^{-3}$ & $3.10(1.30-8.41)$ \\
\hline $\begin{array}{l}\text { GeneID-North population } \\
(1,354 / 1,471)\end{array}$ & A & 0.0085 vs. 0.0027 & $3.33 \times 10^{-3}$ & $3.14(1.40-7.04)$ & 0.01 & $2.74(1.28-7.66)$ \\
\hline $\begin{array}{l}\text { Combined population } \\
(2,794 / 4,131)\end{array}$ & A & 0.0065 vs. 0.0018 & $1.57 \times 10^{-5}$ & $3.58(1.96-6.57)$ & $3.41 \times 10^{-4}$ & $2.80(1.30-6.01)$ \\
\hline
\end{tabular}

Abbreviations: P-obs: $P$ value observed; $P$-adj: $P$ value with adjustment; $O R$ : odds ratio. ${ }^{\text {a }}$ Unadjusted $P$ value and odds ratio (OR) using Chi-square tests with Pearson's $2 \times 2 .{ }^{\text {b}}$ Adjusted $P$ value by multivariate logistic regression analysis for potential confounders including age, gender, hypertension, diabetes mellitus and lipid concentrations (Tch, TG, HDL-c and LDL-c).

Based on its position and the prediction results, we hypothesized that rs34166160 may be associated with the expression level of NINJ2 and enrolled 89 healthy study subjects undergoing annual physical examinations into GeneID to perform eQTL analysis. We measured the mRNA expression levels of NINJ2 using blood samples from 9 people with heterozygous genotype of rs34166160 (AC genotype) and 80 people with wildtype of rs34166160 (CC genotype). The results demonstrated that the mean relative expression level of NINJ2 in the 9 AC genotype carriers was significantly higher than that in the 80 CC genotype carriers ( $p=0.02$, by a KruskalWallis test) (Figure 1). These data suggest that the minor and risk A allele of rs34166160 is associated with an increased expression level of NINJ2 mRNA.

\section{Rs34166160 exhibits allelic differences in transcriptional activity via CCAAT-box/enhancer- binding protein beta (C/EBP beta)}

Through transcript factor binding prediction analysis, we found rs34166160 located in the C/EBP beta binding region in both the PROMO (http://alggen.lsi.upc.es/) and JASPAR (http://jaspar.genereg.net/) database (Figure 2A). First, we tested whether C/EBP beta can affect the expression level of NINJ2 in Human Umbilical Vein Endothelial Cells (HUVEC). The siRNA approach was used to knockdown the expression of C/EBP beta in HUVEC, and the results showed that compared to controls, expression of NINJ2 was decreased by knocking down the expression of C/EBP beta in HUVEC $(p<0.05)$ (Figure 2B).

To validate whether the genomic region overlapping rs34166160 has regulatory activity and effect as a potential enhancer, we cloned a 1020 bp length genomic fragment overlapping rs34166160 harboring each allele into the PGL-3-promoter luciferase vector which contains a minimal SV-40 promoter. We first performed Dual-luciferase assays in Hela cells which did not express C/EBP beta. The results seemed to be no significant difference in transcriptional activity between fragments containing the $\mathrm{C}$ allele and $\mathrm{A}$ allele of rs34166160 without C/EBP beta expression in Hela cells (Figure 3A). However, when the luciferase transcriptional reporter assays were performed under the condition of exogenous overexpression of C/EBP beta in Hela cells, the DNA segment containing A allele of rs34166160 was about 1.3-fold than the DNA segment contained $\mathrm{C}$ allele of rs34166160 $(p<0.05)$ (Figure $3 \mathrm{~A})$. To further investigate the allelic differences in transcriptional activity of rs34166160, we cloned a 30 bp length core genomic segment overlapping rs34166160 harboring each allele into the PGL-3promoter luciferase vectors containing a minimal SV-40 promoter and performed the transcriptional reporter assays same as above. The data showed the same results as the $1020 \mathrm{bp}$ length segment, and the A allele of rs34166160 showed more luciferase activity than the DNA segment containing the $\mathrm{C}$ allele of rs34166160 ( $P$ $<0.05$ ) (Figure 3B). The data suggest that variant rs34166160 impacts as an enhancer, and thereby may be a functional variant at the $12 \mathrm{p} 13$ locus for CAD.

We also performed EMSA assay using HUVEC nuclear extracts and probes flanking the genomic region of rs34166160 which is located in chr12:622,485-622,524 (hg38). Incubation of biotin-labeled probes with different allele of rs34166160 will combined with protein of nuclear extracts from HUVEC, and the probe with A allele showed more binding activity than $\mathrm{C}$ allele (Figure 3C). An addition of a 200-fold excess of unlabelled sequence was used to see whether the DNA-protein interaction is specific. The results demonstrated that rs34166160 exhibits allelic differences in transcriptional activity, and may be induced via $\mathrm{C} / \mathrm{EBP}$ beta.

All these data suggest that the A allele of rs34166160, which confers more risk to $\mathrm{CAD}$, have a higher transcriptional activity compared with the non-risk $\mathrm{C}$ allele under the condition of overexpression of $\mathrm{C} / \mathrm{EBP}$ beta. 


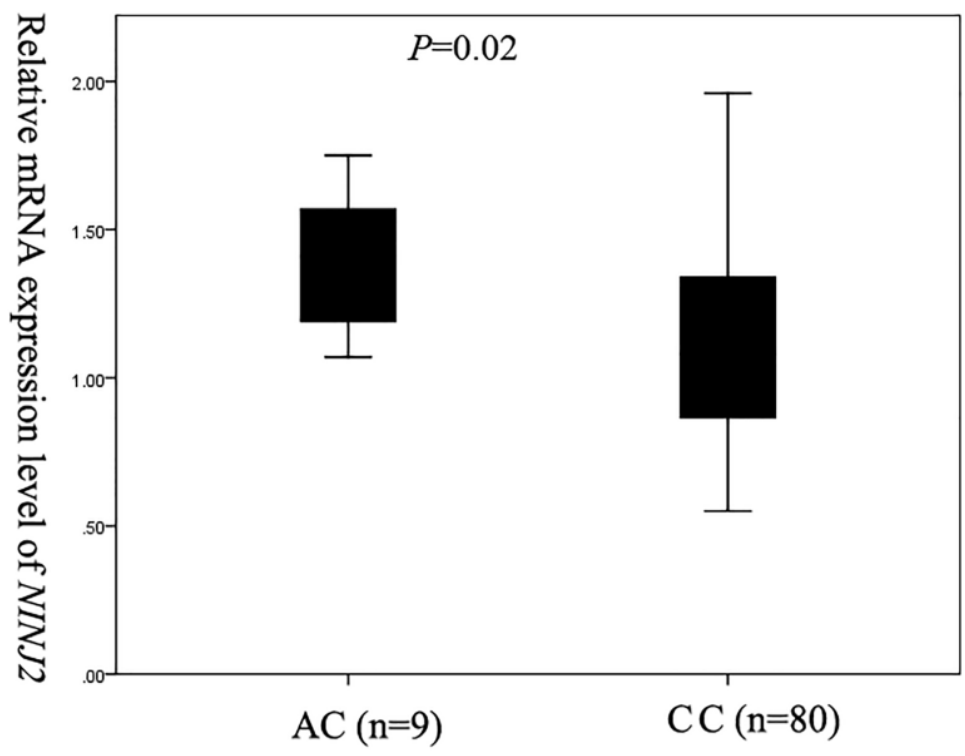

Genotype of rs34166160

Figure 1. Assessment of the relationship between NINJ2 SNP rs34166160 and the expression level of NINJ2 mRNA by realtime RT-PCR analysis. Total RNA samples were isolated from blood samples (lymphocytes) of 9 subjects with an AC genotype and 80 subjects with a CC genotype. Real-time PCR analysis was used to analyze the relative expression level of NINJ2. A linear regression was used to compare the differences in the mean RQ values between different genotypes (AC and CC) of SNP rs34166160.

A

RS34166160

RS34166160-C

AGCCTCTGTCCCCCTCCCCACTGCTACCCGA

RS34166160-A

AGCCTCTGTCCCCCTCCCAACTGCTACCCGA

$\mathrm{C} / \mathrm{EBPB}$ binding site

B
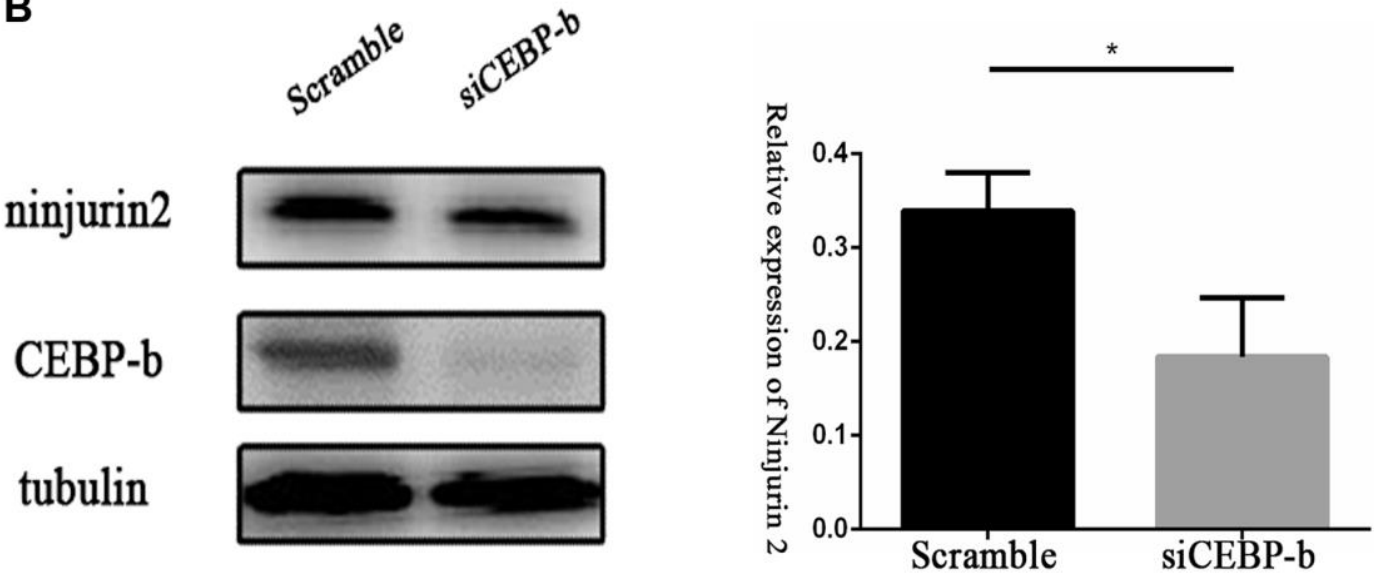

Figure 2. Transcriptional factor CCAAT-box/enhancer-binding protein beta (C/EBP beta) regulates the expression of NINJ2. (A) A schematic diagram shows the predicted binding sites of C/EBP beta in the genomic region overlapping rs34166160 harbored A allele not $\mathrm{C}$ allele. (B) Knockdown of the expression of C/EBP beta in HUVEC resulted in the decrease of NINJ2 expression $(P<0.05)$. HUVECs were pretreated with scramble siRNA or C/EBP beta siRNA for $48 \mathrm{~h}$, total protein extracts were prepared and blotted with the antibodies specific for NINJ2. Three independent experiments were performed. Error bars represent standard deviation (SD). 
Risk allele A of rs34166160 has a higher transcriptional activity under the condition of endothelial activation by LPS stimuli

Previous studies have shown that NINJ2 can regulate LPS-induced endothelial activation and inflammation by interacting with TLR4, and the expression of ninjurin2 in HUVEC could be induced by LPS [19]. Vascular inflammation is known to be the critical and initial step in atherosclerosis. In addition, C/EBP beta was reported to mediate LPS-induced endothelial activation and inflammation. Therefore, we

A pGL3-promoter-1020bp-A pGL3-promoter-1020bp-C pGL3-promoter pGL3-promoter-1020bp-A pGL3-promoter-1020bp-C pGL3-promoter

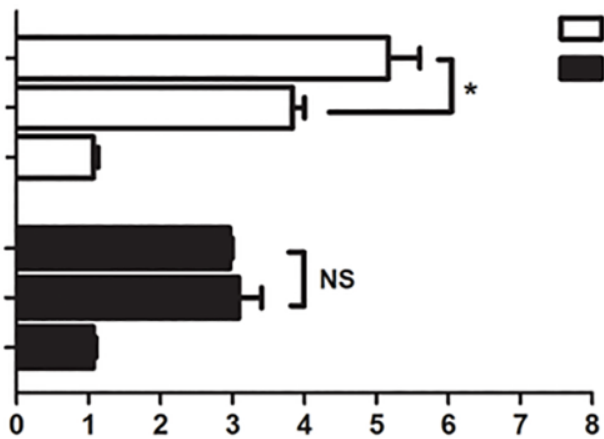

pENTER-C/EBPB PENTER

B

Relative luciferase activity

pGL3-promoter-30bp-A

pGL3-promoter-30bp-C

pGL3-promoter

pGL3-promoter-30bp-A

pGL3-promoter-30bp-C

pGL3-promoter

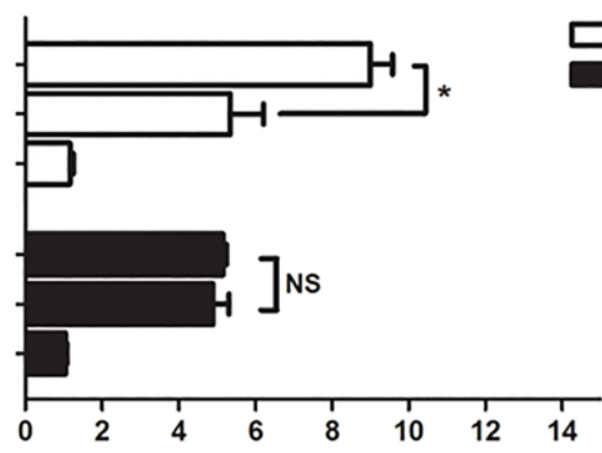

Relative luciferase activity

C

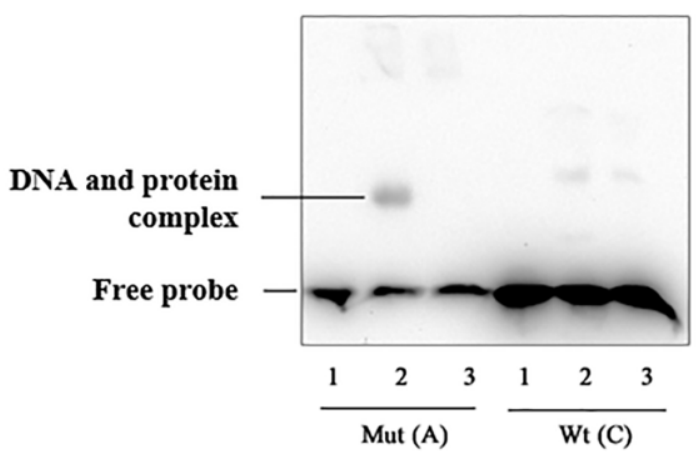

Figure 3. Risk allele A of rs 34166160 exhibits a higher transcriptional activity through interacting with C/EBP beta. (A) Data from luciferase assays in Hela cells. Reporters containing the 1020 bp length genomic fragment overlapping rs34166160 harbored A allele or C allele were co-transfected with PENTER-C/EBP beta or a negative control pENTER into Hela cells. Cells were harvested $48 \mathrm{~h}$ after transfection and luciferase activities were measured and normalized to renilla activities. (B) Data from luciferase assays in Hela cells. Reporters containing a 30 bp length core genomic segment overlapping rs34166160 harboring the A allele or C allele were co-transfected with PENTER-C/EBP beta or a negative control PENTER into Hela cells. The measurement of luciferase activities was previously described. Three independent experiments were performed. Error bars represent standard deviation (SD). ${ }^{*} P<0.05$. (C) The risk allele $A$ of rs 34166160 can directly bind to the transcription factor C/EBP beta. EMSA probe containing risk allele A or wide type allele $\mathrm{C}$ of rs34166160 incubated with (lanes 2-3; lane 5-6) or without (lane 1; lane 4) nuclear extracts from HUVECs transfected with pENTER-C/EBP beta. Lane 1 and lane 4, $5^{\prime}$-end biotin-labeled probe alone; lane 2 and lane 5, EMSA for $5^{\prime}$-end biotin-labeled probe and HUVECs nuclear extracts; lane3 and lane 6, excessive unlabelled probe and HUVECs nuclear extract. 
hypothesized that the enhancer containing rs34166160 might mediate the LPS-induced increase in NINJ2 expression in HUVECs.

To determine whether rs34166160 is involved in endothelial cell activation and inflammation induced by LPS stimulation, the PGL-3-promoter luciferase vectors containing the $30 \mathrm{bp}$ length genomic fragment overlapping rs34166160 harboring each allele were transfected into HUVEC, and the transcriptional activity was measured using luciferase assay with or without LPS stimuli. The results showed that there were no significant differences in luciferase activity between A allele and C allele without stimulation of LPS (Figure 4). However, under the stimulation of LPS, the A allele of rs34166160 showed more luciferase activity than the DNA segment containing C allele of rs34166160 (Figure 4). These results indicated that the A allele of rs34166160, which is shown to confer more risk to $\mathrm{CAD}$, have a higher transcriptional activity compared with non-risk $\mathrm{C}$ allele under inflammatory stimuli, and may have allelic differences in the process of inflammation.

We also investigated the expression level of C/EBP beta and ninjurin2 in HUVEC in the condition of LPS stimuli ( $1 \mathrm{ug} / \mathrm{mL}$ ), and the results showed that both C/EBP beta and ninjurin2 expression were increased after LPS stimulation (Figure 5A). What is more, the increased expression of ninjurin2 induced by LPS stimulation can be blocked by knockdown of C/EBP beta (Figure 5B). These results indicated that rs34166160 plays an important role in LPS inducing endothelial cell activation through the binding of C/EBP beta transcription factor.

\section{DISCUSSION}

In the current study, we carried out a genetic association study to test the hypothesis that whether rs34166160 in NINJ2 confers risk to CAD. Our results demonstrated that the minor A allele of a rare variant, rs34166160, in the NINJ2 gene was conferring risk to CAD in both two independent populations (Table 2). The association of rs34166160 and CAD remained significant after adjustment of the covariates of traditional risk factors (Table 2). Moreover, we found that rs34166160 exhibits allelic differences in transcriptional activity through interacting with $\mathrm{C} / \mathrm{EBP}$ beta or under stimulation of LPS. As far as we know, this is the first study that showed variant in NINJ2 associated with the risk of CAD. Considering the previous significant association between rs34166160 and stroke, our study demonstrated that rs34166160 in the NINJ2 gene may be a shared genetic risk factor for CAD and stroke.

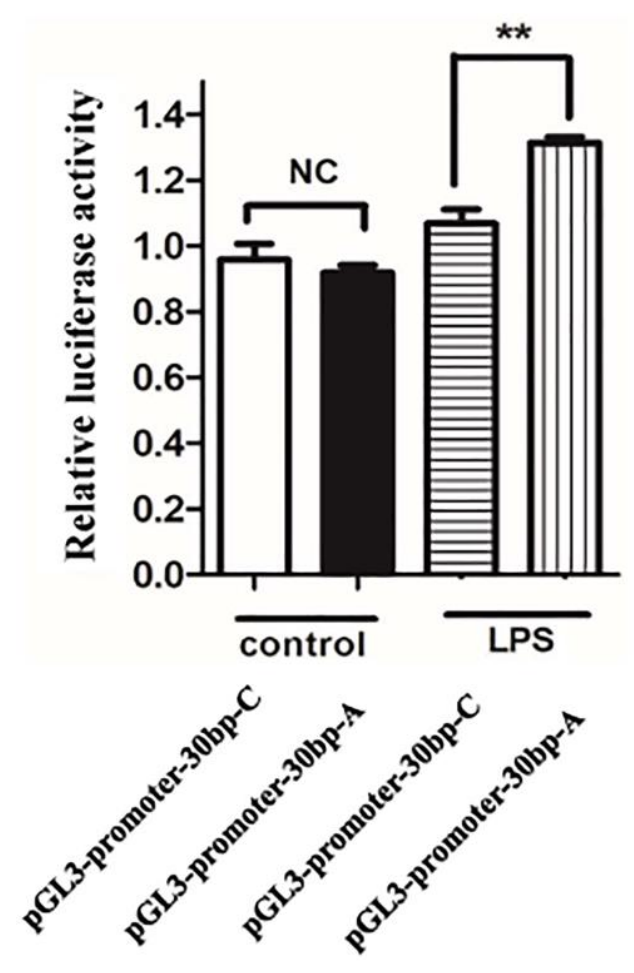

Figure 4. The risk allele A of rs34166160 has a higher transcriptional activity under the condition of LPS stimuli. Data from luciferase assays in HUVECs. The PGL-3-promoter luciferase vectors containing the $30 \mathrm{bp}$ length genomic fragment overlapping rs34166160 harboring risk A allele or wide type C allele were transfect into HUVECs for $24 \mathrm{~h}$, and then LPS (1 ug/ml) stimulated for another $24 \mathrm{~h}$. The measurement of luciferase activities was previously described. Three independent experiments were performed. Error bars represent standard deviation (SD). ${ }^{*} P<0.05$. 
Our association studies between the NINJ2 variant and CAD were performed in Chinese Han population, and whether the significant association can be replicated in other populations needs to be studied further. We searched the summary statistics of several large GWAS about CAD/MI, including CARDIoGRAMplusC4D Consortium and UK biobank, for the low allele frequency, rs34166160, is not part of the list of the imputation based on meta-GWAS results. Therefore, no data could be found for the association between rs34166160 and related traits. In 2010, we performed a GWAS for CAD in Chinese [19], we also tried to search for the association between rs34166160 and CAD in our previous GWAS. Genotypes of GWAS data were first pre-phased at chromosome levels by SHAPEIT20 and the untyped genotypes were imputed using a merged reference panel from 1000 Genomes Phase 3 data across all 2,504 samples as reference haplotype data by IMPUTE2 with $4 \mathrm{MB}$ per chunk. The other parameters were default parameters in IMPUTE2. The results showed extremely low imputation quality of rs34166160 (Info $=0.04$ ). So, we speculate that it is difficult to impute the genotype of rs34166160 according to previously GWAS data.

The expression of NINJ2 can be detected in cells directly involved in the inflammatory process of atherosclerosis, including vascular endothelial cells, monocytes, and macrophages [8, 24, 25]. NINJ2 was also found to be expressed on the cell surface and mediate cell adhesion, which is the critical step of inflammation [8]. Our studies showed that the mechanism of rs34166160 confers risk to CAD and stroke may contribute to the allelic difference of transcriptional activity under the condition of LPS stimuli or C/EBP beta overexpression. Considering that LPS stimuli can cause inflammation [26, 27], and C/EBP beta is one of the most important transcription factors in the inflammation process of atherosclerosis $[28,29]$, our study provides evidence that NINJ2 is involved in the pathology of atherosclerosis, and the risk allele A of rs34166160 has a higher sensitivity than $\mathrm{C}$ allele in condition of inflammatory stimuli.

Our previous study demonstrated that ninjurin2 can interact with toll-like receptor 4 , and activate the inflammation and atherosclerosis pathways through AP-

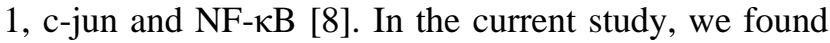
that a functional rare variant in NINJ2 which is located in a C/EBP beta binding site increases the risk of CAD. $C / E B P$ beta is a transcription factor belonging to the basic leucine zipper family, and was found to be expressed in multiple types of cells, including myelomonocytic cells, vascular endothelial cells, macrophages and adipocytes [30, 31]. C/EBP beta plays important roles in inflammation and regulates the
A

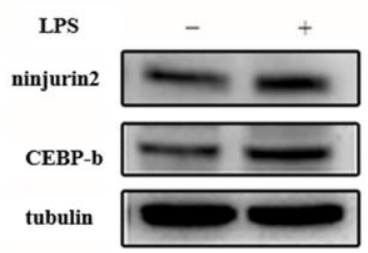

B

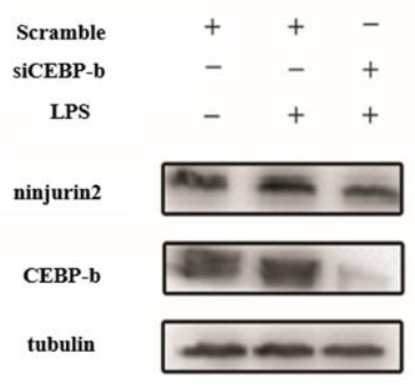

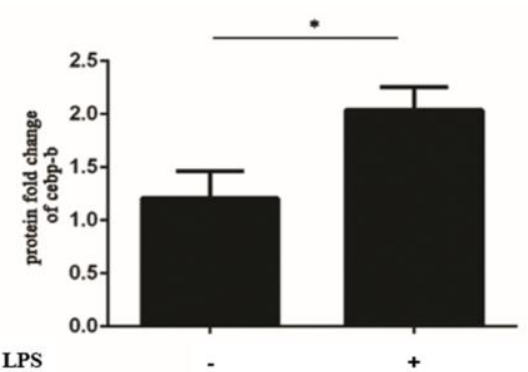

LPS

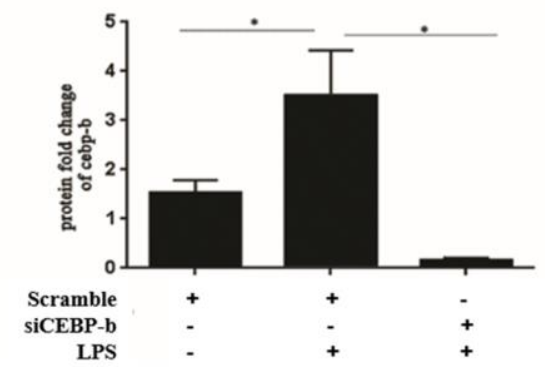

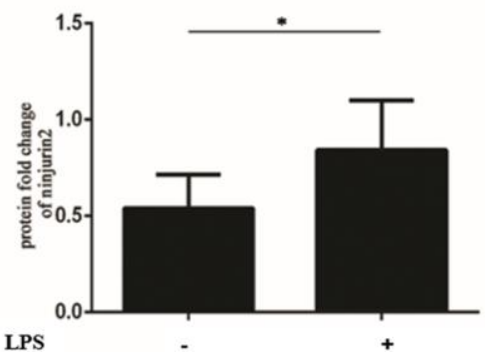

LPS

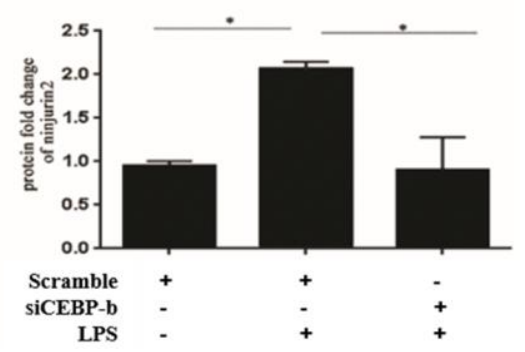

Figure 5. Increased expression of ninjurin2 induced by LPS stimulation can be blocked by knockdown of C/EBP beta. (A) The expression of C/EBP beta and ninjurin2 in HUVEC in the condition of LPS stimuli. HUVEC cells were plated on 24-well plates for $24 \mathrm{~h}$ and followed by stimulation with or without LPS $(1 \mathrm{ug} / \mathrm{mL})$ for another $24 \mathrm{~h}$. Total protein extracts were prepared and blotted with the antibodies specific for NINJ2 or C/EBP beta. Three independent experiments were performed. Error bars represent standard deviation (SD). (B) The increased expression of ninjurin2 induced by LPS stimulation can be blocked by knockdown of C/EBP beta. The si RNA targeted to C/EBP beta were transfect into HUVECs for $24 \mathrm{~h}$, and then LPS (1 ug/ml) stimulated for another $24 \mathrm{~h}$. 
expression of a panel of genes such as TNF, IL-8, IL-1 IL-12, IL-6, NF- $\mathrm{BB}$ and JNK [31-34]. C/EBP beta also exerts key roles in lipid metabolism and inflammation in both the liver and adipose tissue [35]. Rahman et al. found that the reconstitution of bone marrow from $\mathrm{C} / \mathrm{EBP} \beta^{-/}$ mice to irradiated $\mathrm{ApoE}^{-/-}$mice can result in a decrease in the atherosclerotic lesion size [36]. These studies demonstrated that $C / E B P$ beta plays important roles in the process of inflammation and atherosclerosis, and one of the possible mechanisms of C/EBP beta affects inflammation and atherosclerosis may contribute to NINJ2.

In the current study, we used a LPS-stimulated endothelial cell activation or inflammation model to mimic the initiation of atherosclerosis. Several studies have suggested that infectious agents may initiate or promote the inflammatory process in atherosclerosis. In particular, it is believed that LPS from bacteria such as Chlamydia pneumonia [37-39], Helicobacter pylori [40, 41], Porphyromonas gingivalis [42-44] or gut microbiota may be triggering the secretion of inflammatory cytokines that leads to the recruitment of monocytes/macrophages to the lesions in the process of atherosclerosis or coronary artery disease . Elevated levels of LPS seem to present a risk factor for the development of atherosclerosis [45], whereas injection of LPS has been shown to accelerate formation of atherosclerotic lesions [46]. What is more, LPS binds with TLR4, and can induce the activation of TLR4-MyD88$\mathrm{NF}-\mathrm{kB}$ signaling, followed by the release of atherosclerosis related inflammatory factors such as TNF$\alpha, \mathrm{IL}-1 \beta$, IL- 6 , and MCP-1, resulting in the development and progression of atherosclerosis in mice models fed with lipids $[47,48]$. Therefore, the current study also suggests that NINJ2 may participate in the process of endothelial cell activation or inflammation stimulated by infectious agents.

In the Chinese population, the minor allele frequency of rs34166160 is extremely low $(0.13-0.27 \%)$. If the power analysis assumes that the OR for SNP rs34166160 in CAD would be identical to the previously reported HR of 1.8 in stroke, then a limitation of this study may be that the statistical power of our genetic analysis may be insufficient in the two independent populations. Therefore, we cannot exclude the possibility that the significant association between rs34166160 and CAD may represent a false positive result due to the sample size.

In conclusion, for the first time we found that SNP rs34166160 in the NINJ2 gene is associated with the risk of CAD. We also demonstrated rs34166160 associated with the mRNA expression level of NINJ2. In addition, we found that the flanking region of rs34166160 can bind with the transcriptional factor $C / E B P$ beta and the A allele have more transcription activity than the $\mathrm{C}$ allele. What is more, we found that the $\mathrm{A}$ allele has more transcription activity than the $\mathrm{C}$ allele under stimulation of LPS. Our results suggest that NINJ2 is a susceptibility gene for CAD for the first time and that the minor allele A of SNP rs34166160 increases the risk of $\mathrm{CAD}$ by altering the binding activity of transcriptional factor $C / E B P$ beta.

\section{MATERIALS AND METHODS}

\section{Study subjects}

The samples involved in the current research were selected from the GeneID cohort [17, 19, 21]. All participants are of Han nationality according to their self-description. All the research about human subjects was approved by the ethics committee of the university (Huazhong University of Science and Technology, HUST). The study confirms the guidelines set forth by the Declaration of Helsinki, and all study subjects give written informed consent.

Diagnosis of CAD and myocardial infarction (MI) was carried out by two independent expert cardiologists based on the results of coronary angiography. The criteria of myocardial infarction (MI) and CAD were according to the standard ACC/AHA guidelines [49], and as previous studies [50-53]. Patients with greater than $70 \%$ of luminal stenosis in at least one main vessel by coronary angiography, coronary artery bypass graft, percutaneous coronary intervention, and/or MI were diagnosed as CAD patients. The diagnosis of MI was based on typical chest pain of $\geq 30$ min duration, characteristic electrocardiographical patterns of acute MI, and significant elevation of cardiac enzymes (such as CK-MB, lactate dehydrogenase) and troponin I or T. Patients that were identified by angiography with myocardial spasm and myocardial bridge were excluded from the study. Subjects with congenital heart disease, childhood hypertension, and type I diabetes mellitus were also excluded. Control subjects were general population controls and did not show any evidence of CAD or MI as indicated by their medical records or by electrocardiographic analysis.

Basic data such as gender, age, diabetes mellitus, hypertension and lipid concentrations (total cholesterol, triglyceride, LDL cholesterol and HDL cholesterol) were collected from medical records.

\section{SNP genotyping}

Genotyping for SNP rs34166160 was carried out using the TaqMan allelic discrimination assay as previously described [54]. For each round of genotyping, $10 \mathrm{ng}$ of genomic DNA was used in a total volume of $5 \mu \mathrm{l}$ and 
containing 1× TaqMan Genotyping Master Mix (Life Technologies) and $1 \times$ TaqMan SNP genotyping probe (Life Technologies, CA, USA). The PCR reaction and post-PCR endpoint plate reading was carried out using the Applied Biosystems 7900HT Fast Real-Time PCR System (Life Technologies, CA, USA) according to the manufacturer's instructions. To ensure the quality of the experiment, appropriate negative controls were included in each round of genotyping. The genotyping results of TaqMan assay were verified by direct Sanger DNA sequencing of 48 subjects randomly selected.

\section{Real-time quantitative reverse transcription PCR analysis}

Real-Time Quantitative Reverse Transcription PCR (qRT-PCR) was used to determine the mRNA expression level of the NINJ2 among subjects with different genotypes of rs34166160. RNA was obtained from blood sample by Trizol (Life Technologies, CA, USA). Real-Time Quantitative Reverse Transcription PCR Analysis was used to determine the mRNA expression level of the NINJ2 gene among subjects with different genotypes of rs34166160. Quantitative realtime PCR analysis was carried out according to the MIQE guidelines. Total RNA samples were extracted from human peripheral blood leukocytes using Trizol reagent (Life Technologies, CA, USA). Quantification of RNA samples was performed using a spectrophotometer (NanoDrop, Thermo Scientific, NH, USA). $2 \mu \mathrm{g}$ of total RNA was used for reverse transcription with Superscript II reverse transcriptase (Life Technologies, CA, USA) and oligo (dT) 18 . A standard two steps real-time PCR assay was performed using an ABI 7500fast Genetic Analyzer (Life Technologies, CA, USA). The primers for NINJ2 were 5'-ATGCGGCTGAAGGCGGTGCTG-3' (forward) and 5'-TGGCTGCGTTGTTGAGCTGGTTG-3' (reverse). The primers for the $\beta$-actin reference gene (GeneBank ID: $\quad$ BC014861) are 5'-GGACTTCG AGCAGGAGATGG-3' (forward) and 5'-GCACCG TGTTGGCGTAGAGG-3' (reverse). Each PCR reaction was performed in a final volume of $10 \mu \mathrm{L}$ reaction mixture containing $5 \mu \mathrm{L}$ of $2 \mathrm{X}$ PCR master mixture with ROX (Roche Applied Science, IN), $2 \mu \mathrm{L}$ of cDNA, $0.4 \mu \mathrm{L}$ of $10 \mathrm{pM}$ primers, and $2.6 \mu \mathrm{L}$ of ddH2O. Each reaction was performed in triplicate. The cycling conditions were $95^{\circ} \mathrm{C}$ for 10 minutes and 40 cycles of $95^{\circ} \mathrm{C}$ for 15 seconds and $60^{\circ} \mathrm{C}$ elongation for 45 seconds. After the PCR reaction, $\mathrm{Cq}$ values (threshold cycle) of a target gene (NINJ2) (Cq T) or reference gene $\beta$-actin (GeneBank ID: BC014861, Cq E) were computed using the RQ Manager program (version 1.3) and SDS (version 2.3). Reaction with a $\mathrm{Cq}$ of $\geq 40$ or with the difference between $\mathrm{Cq}$ and mean $\mathrm{Cq}$ greater than 0.5 were excluded for further analysis. For each individual, the relative expression level $\Delta \mathrm{Cq}(\mathrm{Cq} \mathrm{T}-\mathrm{Cq}$ E) of a target gene was normalized with the reference gene and then transformed into relative quantity using

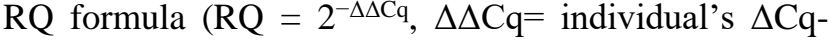
calibrator's $\Delta \mathrm{Cq}$ ). The calibrator was a mixed cDNA sample pooled from 10 randomly selected individuals. The RQ for the calibrator was normalized to 1. After outliers were excluded, a Kruskal-Wallis test (nonparametric analysis of variance) was used to compare the differences for mean RQ values of NINJ2 between different genotypes of SNP rs34166160.

\section{Cell culture and treatment}

HUVEC were obtained from Wuhan Pricells (Wuhan, Hubei, China). Primary Umbilical Vein Endothelial Cells (HUVECs) were obtained from Wuhan Pricells (Wuhan, Hubei, China). The research was performed using 3 distinct cell batches. HUVECs were maintained in endothelial cell medium (ECM, ScienCell, CA, USA) containing Endothelial Cell Growth Supplement (ECGS, ScienCell, CA, USA), 20\% FBS (Gibco, MD, USA), $100 \mathrm{mg} / \mathrm{L}$ heparin (Invitrogen, CA, USA), $1 \mathrm{mM}$ Sodium Pyruvate and $1 \%$ penicillin/streptomycin (Invitrogen, CA, USA) and used at passage 3-6. Hela cells were cultured in DMEM (Gibco, MD, USA) containing $10 \%$ FBS, L-glutamine $(2 \mathrm{mM})$, penicillin $\mathrm{G}$ (100 units $/ \mathrm{ml})$, streptomycin $(10 \mathrm{mg} / \mathrm{ml})$. All cells were grown in an incubator with a humidified atmosphere of $5 \% \mathrm{CO}_{2}$ at $37^{\circ} \mathrm{C}$. Cell were plated in 24 -well plates for $24 \mathrm{~h}$ and accompanied by incubation with or without LPS $(1 \mathrm{ug} / \mathrm{mL})$ for another $24 \mathrm{~h}$.

\section{Expression vector construction}

The predicted 1020 bp length $C / E B P$ beta binding region flanking rs34166160 in the first intron of NINJ2 (Chr12:622,453-623,472, hg38) was generated by PCR and using human genomic DNA as a template. The primer sequences used for amplification are 5'-GAGCTCGGGCTACCTAAAGAGAGGAAGA-3' contained a $S a c$ I restriction enzyme cutting site and 5'-CTCGAGCTTCCCTGATTTTGGCTGGTAC-3' contained a Xho I site. The $1020 \mathrm{bp}$ length PCR products were digested with Sac I and Xho I, and sub-cloned into the pGL3-Promoter luciferase plasmid (Promega, Madison, WI, USA), resulting in the pGL3-promoter$1020 \mathrm{bp}-\mathrm{A}$ or pGL3-promoter-1020 bp-C plasmid. The 30 bp length fragments flanking rs34166160 was synthesized by Genewiz ltd (Suzhou, China). The DNA fragment (5'-CGGGGTACCTCTGTCCCCCTCCCC CACTGCTACCCGAGCCTCGAGCGG-3' for C allele of rs34166160 and 5'-CGGGGTACCTCTGTCCCCC TCCCCAACTGCTACCCGAGCCTCGAGCGG-3' for A allele of rs34166160) and their corresponding complement chains were annealed and then sub-cloned 
into the pGL3-Promoter luciferase plasmid after digesting by Kpn I and Xho I. Human C/EBP beta ORF (NM_005194) was purchased from Origene (Rockville, MD, USA) and sub-cloned into pENTR vector (Thermo fisher, Pittsburgh, PA, USA).

\section{Luciferase reporter assay}

Hela cells co-transfected with $150 \mathrm{ng}$ of either the pENTER control vector or pENTER-C/EBP beta and 50 ng pGL3-promoter luciferase reporter plasmids contained $\mathrm{C}$ allele or A allele of rs34166160 in a 96-well plate [55]. The transfection efficiency was normalized by cotransfecting of $4 \mathrm{ng}$ pRL-TK plasmid. Cells were lysed using a passive lysis buffer after 48 hours of transfection (Promega, Madison, WI, USA). The dual-luciferase assay was analyzed using the dual-luciferase assay kit (Promega, Madison, WI, USA) using GloMax illuminometer (Promega, Madison, WI, USA).

\section{Western blot}

Western blot was performed as standard protocol [56]. The antibodies used for western blot analysis include an anti- C/EBP beta antibody (1:1500, Proteintech, Wuhan, China), an anti-alpha tubulin (1:5000, Merck Millipore, Darmstadt, Germany) and a goat polyclonal anti-NINJ2 antibody $(1: 1200$, R\&D Systems, Minneapolis, MN, USA).

\section{Electrophoretic Mobility Shift Assay (EMSA)}

pENTER- $C / E B P$ beta plasmid was transfected into HUVEC for 40 hours using Viafect ${ }^{\mathrm{TM}}$ reagent. EMSA probes were designed according to the predicted $C / E B P$ beta binding site on SNP rs34166160. The sequence of wild type $\mathrm{C}$ allele probe (5'-AGCCTCTGTCCCCCT CCCCACTGCTACCCGA-3') and the minor A allele probe (5'-AGCCTCTGTCCCCCTCCCAACTGCTA CCCGA-3') was synthesized in Sangong Biotech and with a 5'-end-labeled biotin. NE-PER Nuclear and Cytoplasmic Extract kit was used to extract nuclear proteins (Thermo fisher, Pittsburgh, PA, USA). $2 \mu \mathrm{g}$ of extracted nuclear protein was hybridized with WT and Mutation DNA probes, respectively. Protein-DNA complexes were analyzed on a $6 \%$ nondenaturing PAGE gel. Excessive unlabeled probes were used as competition for EMSA experiments. LightShift ${ }^{\mathrm{TM}}$ Chemiluminescent EMSA Kit was used for the EMSA assay (Thermo fisher, Pittsburgh, PA, USA).

\section{Statistical analysis}

For genetic association studies, statistical analysis was carried out as previously reported [17, 21]. Pearson's $2 \times 2$ contingency tables and Chi-square tests as implemented in PLINK version 1.08 were used to analyze the SNP allelic association study [57]. Risk factors including lipid concentrations, age, gender, hypertension and diabetes mellitus and lipids profiles were used to adjust the association using multivariate logistic regression analysis. PS:Power and Simple Size Calculation software was used to analyze the statistical power [58]. For western blot and other functional studies, results from at least three independent experiments are shown and presented as mean \pm SD. Student's $t$ tests were used for data analysis between the two groups using GraphPad Prism 6 software. $P<0.05$ means that there is a significant difference between the data and is statistically significant ( ${ }^{*}$ means $\left.P<0.05\right)$.

\section{AUTHOR CONTRIBUTIONS}

Wang PY, Peng $\mathrm{H}$ and Wang YF contributed equally to this study. Study concept and design: Xu C, Wang Qing $\mathrm{K}$. Acquisition of data (experiment of genetic analysis): Wang PY, Wang PX, Zhang $\mathrm{R}$ and Xiong $\mathrm{L}$. Acquisition of data (experiment of western blot, luciferase assay): Wang JJ, Peng H, Wang Y, Zheng Q and Wang J. Critical revision of the manuscript for important intellectual content: Wang Qing K, Xia Y. Statistical analysis: Wang PY and Wang JJ. Obtained funding: $\mathrm{Xu} \mathrm{C}$ and Wang PY. Study supervision: $\mathrm{Xu} \mathrm{C}$ and Wang Qing K.

\section{CONFLICTS OF INTEREST}

The authors declare that the research was conducted in the absence of any commercial or financial relationships that could be construed as a potential conflicts of interest.

\section{FUNDING}

This study was supported by the National Natural Science Foundation of China Program (82070355, 81630002 and 32070581), Young and Middle-aged Talents of Wuhan Municipal Health Commission (to Wang PY), Hubei health and family planning scientific research project (WJ2019Q037), National Natural Science Foundation of Hubei (2017CFB322).

\section{REFERENCES}

1. Lim SS, Vos T, Flaxman AD, Danaei G, Shibuya K, Adair-Rohani $H$, Amann $M$, Anderson HR, Andrews KG, Aryee M, Atkinson C, Bacchus LJ, Bahalim AN, et al. A comparative risk assessment of burden of disease and injury attributable to 67 risk factors and risk factor clusters in 21 regions, 1990-2010: a systematic analysis for the Global Burden of Disease Study 2010. Lancet. 2012; 380:2224-60. 
https://doi.org/10.1016/S0140-6736(12)61766-8 PMID:23245609

2. Yin D, Naji DH, Xia Y, Li S, Bai Y, Jiang G, Zhao Y, Wang $X$, Huang $Y$, Chen S, Fa J, Tan C, Zhou M, et al. Genomic Variant in IL-37 Confers A Significant Risk of Coronary Artery Disease. Sci Rep. 2017; 7:42175. https://doi.org/10.1038/srep42175 PMID: 28181534

3. Fox CS, Polak JF, Chazaro I, Cupples A, Wolf PA, D'Agostino RA, O'Donnell $\mathrm{CJ}$, and Framingham Heart Study. Genetic and environmental contributions to atherosclerosis phenotypes in men and women: heritability of carotid intimamedia thickness in the Framingham Heart Study. Stroke. 2003; 34:397-401.

https://doi.org/10.1161/01.str.0000048214.56981.6f PMID:12574549

4. Weber C, Noels H. Atherosclerosis: current pathogenesis and therapeutic options. Nat Med. 2011; 17:1410-22. https://doi.org/10.1038/nm.2538 PMID:22064431

5. Heianza Y, Qi L. Impact of Genes and Environment on Obesity and Cardiovascular Disease. Endocrinology. 2019; 160:81-100.

https://doi.org/10.1210/en.2018-00591 PMID: 30517623

6. Lusis AJ. Genetics of atherosclerosis. Trends Genet. 2012; 28:267-75.

https://doi.org/10.1016/j.tig.2012.03.001

PMID:22480919

7. Dichgans M, Malik R, König IR, Rosand J, Clarke R, Gretarsdottir S, Thorleifsson G, Mitchell BD, Assimes TL, Levi C, O'Donnell CJ, Fornage M, Thorsteinsdottir $U$, et al, and METASTROKE Consortium, and CARDIoGRAM Consortium, and C4D Consortium, and International Stroke Genetics Consortium. Shared genetic susceptibility to ischemic stroke and coronary artery disease: a genome-wide analysis of common variants. Stroke. 2014; 45:24-36.

https://doi.org/10.1161/STROKEAHA.113.002707 PMID:24262325

8. Wang J, Fa J, Wang $P$, Jia $X$, Peng $H$, Chen J, Wang $Y$, Wang C, Chen Q, Tu X, Wang QK, Xu C. NINJ2- A novel regulator of endothelial inflammation and activation. Cell Signal. 2017; 35:231-41. https://doi.org/10.1016/j.cellsig.2017.04.011 PMID:28431986

9. Wang L, Zhao C, Xia QX, Qiao SJ. Association between 12p13 SNP rs11833579 and ischemic stroke in Asian population: An updated meta-analysis. J Neurol Sci. 2014; 345:198-201. https://doi.org/10.1016/i.jns.2014.07.047 PMID:25096477

10. Li BH, Zhang LL, Yin YW, Pi Y, Guo L, Yang QW, Gao CY, Fang CQ, Wang JZ, Li JC. Association between 12p13 SNPs rs11833579/rs12425791 near NINJ2 gene and ischemic stroke in East Asian population: evidence from a meta-analysis. J Neurol Sci. 2012; 316:116-21. https://doi.org/10.1016/i.jns.2012.01.010 PMID:22297388

11. Zhu Y, Liu K, Tang $X$, Wang J, Yu Z, Wu Y, Chen D, Wang $X$, Fang K, Li N, Huang S, Hu Y. Association between NINJ2 gene polymorphisms and ischemic stroke: a family-based case-control study. J Thromb Thrombolysis. 2014; 38:470-6. https://doi.org/10.1007/s11239-014-1065-6 PMID:24664524

12. Ikram MA, Seshadri S, Bis JC, Fornage $M$, DeStefano $A L$, Aulchenko YS, Debette S, Lumley T, Folsom AR, van den Herik EG, Bos MJ, Beiser A, Cushman M, et al. Genomewide association studies of stroke. N Engl J Med. 2009; 360:1718-28. https://doi.org/10.1056/NEJMoa0900094 PMID: 19369658

13. Wan XH, Li SJ, Cheng P, Zhang Q, Yang XC, Zhong GZ, $\mathrm{Hu}$ WL, Jin L, Wang XF. NINJ2 polymorphism is associated with ischemic stroke in Chinese Han population. J Neurol Sci. 2011; 308:67-71. https://doi.org/10.1016/i.jns.2011.06.011 PMID:21722921

14. Zhang Z, Ni G, Xu G, Xu J, Liu X. A Novel Functional Polymorphism in the NINJ2 Promoter Predicts Risk of Large Artery Atherosclerotic Stroke. Mol Neurobiol. 2016; 53:7178-83. https://doi.org/10.1007/s12035-015-9619-y PMID:26687183

15. Bis JC, DeStefano A, Liu X, Brody JA, Choi SH, Verhaaren BF, Debette S, Ikram MA, Shahar E, Butler KR Jr, Gottesman RF, Muzny D, Kovar CL, et al. Associations of NINJ2 sequence variants with incident ischemic stroke in the Cohorts for Heart and Aging in Genomic Epidemiology (CHARGE) consortium. PLoS One. 2014; 9:e99798.

https://doi.org/10.1371/journal.pone.0099798 PMID:24959832

16. Xiong $X, X u C$, Zhang $Y$, Li X, Wang B, Wang F, Yang $Q$, Wang D, Wang $X$, Li S, Chen S, Zhao Y, Yin D, et al. BRG1 variant rs1122608 on chromosome 19p13.2 confers protection against stroke and regulates expression of pre-mRNA-splicing factor SFRS3. Hum Genet. 2014; 133:499-508.

https://doi.org/10.1007/s00439-013-1389-x

PMID:24190014 
17. Xu C, Yang Q, Xiong H, Wang L, Cai J, Wang F, Li S, Chen J, Wang C, Wang D, Xiong X, Wang $\mathrm{P}$, Zhao $\mathrm{Y}$, et al. Candidate pathway-based genome-wide association studies identify novel associations of genomic variants in the complement system associated with coronary artery disease. Circ Cardiovasc Genet. 2014; 7:887-94. https://doi.org/10.1161/CIRCGENETICS.114.000738 PMID:25249547

18. Wang $P$, Yang $Q$, Wu $X$, Yang $Y$, Shi L, Wang C, Wu G, Xia Y, Yang B, Zhang R, Xu C, Cheng X, Li S, et al. Functional dominant-negative mutation of sodium channel subunit gene SCN3B associated with atrial fibrillation in a Chinese GeneID population. Biochem Biophys Res Commun. 2010; 398:98-104.

https://doi.org/10.1016/j.bbrc.2010.06.042 PMID:20558140

19. Wang F, Xu CQ, He Q, Cai JP, Li XC, Wang D, Xiong X, Liao YH, Zeng QT, Yang YZ, Cheng X, Li C, Yang R, et al. Genome-wide association identifies a susceptibility locus for coronary artery disease in the Chinese Han population. Nat Genet. 2011; 43:345-49.

https://doi.org/10.1038/ng.783

PMID:21378986

20. Ren $X, X u$ C, Zhan $C$, Yang $Y$, Shi L, Wang F, Wang $C$, Xia $Y$, Yang B, Wu G, Wang $P$, Li X, Wang D, et al. Identification of NPPA variants associated with atrial fibrillation in a Chinese GeneID population. Clin Chim Acta. 2010; 411:481-5.

https://doi.org/10.1016/i.cca.2009.12.019 PMID:20064500

21. Xu C, Wang F, Wang B, Li X, Li C, Wang D, Xiong $X$, Wang $P$, Lu Q, Wang $X$, Yang $Q$, Yin D, Huang $Y$, et al. Minor allele $\mathrm{C}$ of chromosome 1p32 single nucleotide polymorphism rs11206510 confers risk of ischemic stroke in the Chinese Han population. Stroke. 2010; 41:1587-92.

https://doi.org/10.1161/STROKEAHA.110.583096 PMID:20576952

22. Xiong $X$, Naji DH, Wang B, Zhao $Y$, Wang J, Wang D, Zhang $Y$, Li S, Chen S, Huang $Y$, Yang $Q$, Wang $X$, Yin D, et al. Significant Association between OPG/TNFRSF11B Variant and Common Complex Ischemic Stroke. J Stroke Cerebrovasc Dis. 2018; 27:1683-91.

https://doi.org/10.1016/j.jstrokecerebrovasdis.2018. 01.029

PMID:29501268

23. Xiong $H$, Yang $Q$, Zhang $X$, Wang $P$, Chen $F$, Liu $Y$, Wang $P$, Zhao $Y$, Li S, Huang $Y$, Chen S, Wang $X$, Zhang $H$, et al. Significant association of rare variant p.Gly8Ser in cardiac sodium channel $\beta 4$-subunit SCN4B with atrial fibrillation. Ann Hum Genet. 2019; 83:239-48.

https://doi.org/10.1111/ahg.12305

PMID: $\underline{30821358}$
24. Araki T, Zimonjic DB, Popescu NC, Milbrandt J. Mechanism of homophilic binding mediated by ninjurin, a novel widely expressed adhesion molecule. J Biol Chem. 1997; 272:21373-80.

https://doi.org/10.1074/jbc.272.34.21373

PMID: $\underline{9261151}$

25. Chadwick BP, Heath SK, Williamson J, Obermayr F, Patel L, Sheer D, Frischauf AM. The human homologue of the ninjurin gene maps to the candidate region of hereditary sensory neuropathy type I (HSNI). Genomics. 1998; 47:58-63. https://doi.org/10.1006/geno.1997.5084 PMID:9465296

26. Hansson GK. Inflammation, atherosclerosis, and coronary artery disease. N Engl J Med. 2005; 352:1685-95.

https://doi.org/10.1056/NEJMra043430 PMID:15843671

27. Stoll LL, Denning GM, Weintraub NL. Potential role of endotoxin as a proinflammatory mediator of atherosclerosis. Arterioscler Thromb Vasc Biol. 2004; 24:2227-36.

https://doi.org/10.1161/01.ATV.0000147534.69062.dc PMID: 15472123

28. Payne VA, Au WS, Lowe CE, Rahman SM, Friedman JE, O'Rahilly S, Rochford JJ. C/EBP transcription factors regulate SREBP1C gene expression during adipogenesis. Biochem J. 2009; 425:215-23. https://doi.org/10.1042/BJ20091112 PMID:19811452

29. Reschen ME, Gaulton KJ, Lin D, Soilleux EJ, Morris AJ, Smyth SS, O'Callaghan CA. Lipid-induced epigenomic changes in human macrophages identify a coronary artery disease-associated variant that regulates PPAP2B Expression through Altered C/EBP-beta binding. PLoS Genet. 2015; 11:e1005061. https://doi.org/10.1371/journal.pgen.1005061 PMID:25835000

30. Manea SA, Todirita A, Raicu M, Manea A. C/EBP transcription factors regulate $\mathrm{NADPH}$ oxidase in human aortic smooth muscle cells. J Cell Mol Med. 2014; 18:1467-77. https://doi.org/10.1111/jcmm.12289 PMID:24797079

31. Huber R, Pietsch D, Panterodt T, Brand K. Regulation of $C / E B P \beta$ and resulting functions in cells of the monocytic lineage. Cell Signal. 2012; 24:1287-96. https://doi.org/10.1016/i.cellsig.2012.02.007 PMID:22374303

32. Gorgoni B, Maritano D, Marthyn P, Righi M, Poli V. $\mathrm{C} / \mathrm{EBP}$ beta gene inactivation causes both impaired and enhanced gene expression and inverse regulation 
of IL-12 p40 and p35 mRNAs in macrophages. J Immunol. 2002; 168:4055-62.

https://doi.org/10.4049/jimmunol.168.8.4055 PMID:11937564

33. Rahman SM, Janssen RC, Choudhury M, Baquero KC, Aikens RM, de la Houssaye BA, Friedman JE. CCAAT/enhancer-binding protein $\beta \quad(C / E B P \beta)$ expression regulates dietary-induced inflammation in macrophages and adipose tissue in mice. J Biol Chem. 2012; 287:34349-60.

https://doi.org/10.1074/jbc.M112.410613

PMID:22902781

34. Thomas SR. Haematopoietic-expressed C/EBP $\beta$ : A novel transcriptional regulator of hepatic liver metabolism and macrophage foam cells during atherosclerosis? Atherosclerosis. 2016; 250:183-5. https://doi.org/10.1016/i.atherosclerosis.2016.05.015 PMID:27207261

35. Schroeder-Gloeckler JM, Rahman SM, Janssen RC, Qiao L, Shao J, Roper M, Fischer SJ, Lowe E, Orlicky DJ, McManaman JL, Palmer C, Gitomer WL, Huang W, et al. CCAAT/enhancer-binding protein beta deletion reduces adiposity, hepatic steatosis, and diabetes in Lepr(db/db) mice. J Biol Chem. 2007; 282:15717-29. https://doi.org/10.1074/ibc.M701329200 PMID:17387171

36. Rahman SM, Baquero KC, Choudhury M, Janssen RC, de la Houssaye BA, Sun M, Miyazaki-Anzai S, Wang S, Moustaid-Moussa N, Miyazaki M, Friedman JE. $C / E B P \beta$ in bone marrow is essential for diet induced inflammation, cholesterol balance, and atherosclerosis. Atherosclerosis. 2016; 250:172-9. https://doi.org/10.1016/i.atherosclerosis.2016.03.040 PMID:27072340

37. Grayston JT, Kuo CC, Coulson AS, Campbell LA, Lawrence RD, Lee MJ, Strandness ED, Wang SP. Chlamydia pneumoniae (TWAR) in atherosclerosis of the carotid artery. Circulation. 1995; 92:3397-400.

https://doi.org/10.1161/01.cir.92.12.3397 PMID:8521559

38. Grayston JT. Background and current knowledge of Chlamydia pneumoniae and atherosclerosis. J Infect Dis. 2000 (Suppl 3); 181:S402-10.

https://doi.org/10.1086/315596

PMID:10839724

39. Schumacher A, Seljeflot I, Lerkerød AB, Sommervoll L, Otterstad JE, Arnesen H. Does infection with Chlamydia pneumoniae and/or Helicobacter pylori increase the expression of endothelial cell adhesion molecules in humans? Clin Microbiol Infect. 2002; 8:654-61. https://doi.org/10.1046/j.1469-0691.2002.00439.x PMID: $\underline{12390284}$
40. Danesh J, Youngman L, Clark S, Parish S, Peto R, Collins R. Helicobacter pylori infection and early onset myocardial infarction: case-control and sibling pairs study. BMJ. 1999; 319:1157-62.

https://doi.org/10.1136/bmj.319.7218.1157 PMID:10541503

41. Danesh J, Peto R. Risk factors for coronary heart disease and infection with Helicobacter pylori: metaanalysis of 18 studies. BMJ. 1998; 316:1130-32.

https://doi.org/10.1136/bmj.316.7138.1130 PMID:9552950

42. Hajishengallis G, Martin M, Schifferle RE, Genco RJ. Counteracting interactions between lipopolysaccharide molecules with differential activation of toll-like receptors. Infect Immun. 2002; 70:6658-64.

https://doi.org/10.1128/IAl.70.12.6658-6664.2002 PMID:12438339

43. Gibson FC 3rd, Yumoto H, Takahashi Y, Chou HH, Genco CA. Innate immune signaling and Porphyromonas gingivalis-accelerated atherosclerosis. J Dent Res. 2006; 85:106-21.

https://doi.org/10.1177/154405910608500202 PMID: $\underline{16434728}$

44. Roth GA, Moser B, Huang SJ, Brandt JS, Huang $Y$, Papapanou PN, Schmidt AM, Lalla E. Infection with a periodontal pathogen induces procoagulant effects in human aortic endothelial cells. J Thromb Haemost. 2006; 4:2256-61.

https://doi.org/10.1111/i.1538-7836.2006.02128.x PMID: 16856978

45. Kiechl S, Egger G, Mayr M, Wiedermann CJ, Bonora E, Oberhollenzer F, Muggeo M, Xu Q, Wick G, Poewe W, Willeit J. Chronic infections and the risk of carotid atherosclerosis: prospective results from a large population study. Circulation. 2001; 103:1064-70.

https://doi.org/10.1161/01.cir.103.8.1064

PMID:11222467

46. Lehr HA, Sagban TA, Ihling C, Zähringer $U$, Hungerer $K D$, Blumrich $M$, Reifenberg $K$, Bhakdi $S$. Immunopathogenesis of atherosclerosis: endotoxin accelerates atherosclerosis in rabbits on hypercholesterolemic diet. Circulation. 2001; 104:914-20.

https://doi.org/10.1161/hc3401.093153 PMID:11514379

47. Falck-Hansen M, Kassiteridi C, Monaco C. Toll-like receptors in atherosclerosis. Int J Mol Sci. 2013; 14:14008-23.

https://doi.org/10.3390/ijms140714008 PMID: 23880853

48. Kapelouzou A, Giaglis S, Peroulis M, Katsimpoulas M, Moustardas P, Aravanis CV, Kostakis A, Karayannakos PE, Cokkinos DV. Overexpression of Toll-Like 
Receptors 2, 3, 4, and 8 Is Correlated to the Vascular Atherosclerotic Process in the Hyperlipidemic Rabbit Model: The Effect of Statin Treatment. J Vasc Res. 2017; 54:156-69.

https://doi.org/10.1159/000457797

PMID:28478461

49. Krumholz HM, Anderson JL, Brooks NH, Fesmire FM, Lambrew CT, Landrum MB, Weaver WD, Whyte J, Bonow RO, Bennett SJ, Burke G, Eagle KA, Linderbaum $\mathrm{J}$, et al, and American College of Cardiology/American Heart Association Task Force on Performance Measures, and Writing Committee to Develop Performance Measures on ST-Elevation and Non-STElevation Myocardial Infarction. ACC/AHA clinical performance measures for adults with ST-elevation and non-ST-elevation myocardial infarction: a report of the American College of Cardiology/American Heart Association Task Force on Performance Measures (Writing Committee to Develop Performance Measures on ST-Elevation and Non-ST-Elevation Myocardial Infarction). Circulation. 2006; 113:732-61. https://doi.org/10.1161/CIRCULATIONAHA.106.172860 PMID:16391153

50. Chen S, Wang X, Wang J, Zhao Y, Wang D, Tan C, Fa J, Zhang R, Wang F, Xu C, Huang Y, Li S, Yin D, et al. Genomic variant in CAV1 increases susceptibility to coronary artery disease and myocardial infarction. Atherosclerosis. 2016; 246:148-56. https://doi.org/10.1016/j.atherosclerosis.2016.01.008 PMID:26775120

51. Naji DH, Tan C, Han F, Zhao Y, Wang J, Wang D, Fa J, Li S, Chen S, Chen Q, Xu C, Wang QK. Significant genetic association of a functional TFPI variant with circulating fibrinogen levels and coronary artery disease. Mol Genet Genomics. 2018; 293:119-28.

https://doi.org/10.1007/s00438-017-1365-6

PMID:28894953

52. Tu X, Nie S, Liao Y, Zhang H, Fan Q, Xu C, Bai Y, Wang F, Ren X, Tang T, Xia N, Li S, Huang Y, et al. The IL-33ST2L pathway is associated with coronary artery disease in a Chinese Han population. Am J Hum Genet. 2013; 93:652-60.

https://doi.org/10.1016/i.ajhg.2013.08.009

PMID:24075188
53. Cheng $X$, Shi L, Nie S, Wang F, Li X, Xu C, Wang P, Yang B, Li Q, Pan Z, Li Y, Xia H, Zheng C, et al. The same chromosome 9p21.3 locus is associated with type 2 diabetes and coronary artery disease in a Chinese Han population. Diabetes. 2011; 60:680-4.

https://doi.org/10.2337/db10-0185

PMID:21270277

54. Wang P, Xu C, Wang C, Wu Y, Wang D, Chen S, Zhao Y, Wang X, Li S, Yang Q, Zeng Q, Tu X, Liao Y, et al. Association of SNP Rs9943582 in APLNR with Left Ventricle Systolic Dysfunction in Patients with Coronary Artery Disease in a Chinese Han GenelD Population. PLoS One. 2015; 10:e0125926. https://doi.org/10.1371/journal.pone.0125926 PMID:25993436

55. Luo C, Pook E, Wang F, Archacki SR, Tang B, Zhang W, Hu JS, Yang J, Leineweber K, Bechem M, Huang W, Song $\mathrm{Y}$, Cheung $\mathrm{SH}$, et al. ADTRP regulates TFPI expression via transcription factor POU1F1 involved in coronary artery disease. Gene. 2020; 753:144805. https://doi.org/10.1016/i.gene.2020.144805 PMID:32445923

56. Si W, Zhou B, Xie W, Li H, Li K, Li S, Deng W, Shi P, Yuan $C$, Ke T, Ren X, Tu X, Zeng $X$, et al. Angiogenic factor AGGF1 acts as a tumor suppressor by modulating p53 post-transcriptional modifications and stability via MDM2. Cancer Lett. 2021; 497:28-40. https://doi.org/10.1016/j.canlet.2020.10.014 PMID:33069768

57. Wang $\mathrm{P}$, Wang $\mathrm{C}$, Li S, Wang B, Xiong L, Tu X, Wang QK, $\mathrm{Xu}$ CQ. Lack of association between the APLNR variant rs9943582 with ischemic stroke in the Chinese Han GenelD population. Oncotarget. 2017; 8:107678-84. https://doi.org/10.18632/oncotarget.22588 PMID:29296197

58. Dupont WD, Plummer WD Jr. Power and sample size calculations for studies involving linear regression. Control Clin Trials. 1998; 19:589-601. https://doi.org/10.1016/s0197-2456(98)00037-3 PMID: 9875838 